02

\title{
УФ люминесценция и лазерная генерация в ансамблях микрокристаллов оксида цинка с медью
}

\author{
(C) А.М. Ополченцев ${ }^{1}$, Л.А. Задорожная ${ }^{1}$, Ч.М. Брискина ${ }^{2}$, В.М. Маркушев ${ }^{2}$, \\ А.П. Тарасов ${ }^{2,3}$, А.Э. Муслимов ${ }^{1, \uparrow}$, В.М. Каневский ${ }^{1}$ \\ ${ }^{1}$ Институт кристаллограффии им. А.В. Шубникова ФНИЦ „Кристаллография и фотоника“ РАН, \\ 119333 Москва, Россия \\ ${ }^{2}$ ИРЭ им. В.А. Котельникова РАН, \\ 125009 Москва, Россия \\ ${ }^{3}$ Московский фризико-технический институт (ГУ), \\ 141701 Долгопрудный, Московская обл., Россия \\ ๑e-mail: amuslimov@mail.ru
}

Поступила в редакцию 24.05.2018 г.

Массивы микростержней оксида цинка с медью выращены методом химического осаждения из паровой фазы на подложках монокристаллического сапфира, предварительно покрытых слоем меди нанометровой толщины. Экспериментально продемонстрировано, что присутствие меди в образцах микростержней оксида цинка повышает интенсивность фотолюминесценции массивов микрокристаллов $\mathrm{ZnO}$, снижает величину порога лазерной генерации и приводит к небольшому $(\sim 2.5 \mathrm{~nm})$ смещению пика интенсивности излучения микрокристаллов $\mathrm{ZnO}$ в сторону более коротких длин волн. Показано, что характер лазерного излучения зависит от морфологии массивов микростержней $\mathrm{ZnO}$.

DOI: $10.21883 /$ OS.2018.10.46702.142-18

\section{Введение}

Значительный научный и практический интерес к оксиду цинка связан с его уникальными полупроводниковыми свойствами: широкая запрещенная зона $(\sim 3.3 \mathrm{eV}$ при комнатной температуре), высокая энергия связи экситона $(60 \mathrm{meV})$, а также возможность получения микрокристаллов различной морфологии. Вследствие уникальных электрических и оптических свойств нано- и микрокристаллы $\mathrm{ZnO}$ представляют интерес для УФ лазеров, светодиодов и оптических датчиков [1-3]. Особый интерес представляет возможность создания массивов микро- и нанокристаллов $\mathrm{ZnO}$, в которых лазерными резонаторами служат сами кристаллы [4]. Разработаны различные методики, позволяющие синтезировать массивы микрокристаллитов разной морфологии: метод термического роста из солевых матриц [5], зольгель-процесс [6], импульсное лазерное напыление [7], растворные методики [8], химического осаждения из паровой фазы $[9-15,18,21]$, при котором рост полупроводниковых микрокристаллов протекает по механизму пар-жидкость-кристалл (ПЖК) [16]. Помимо этого, значительная часть работ посвящена улучшению пороговых спектрально-генерационных характеристик массивов микрокристаллов оксида цинка. Например, в [17] показано, что порог генерации зависит от длины микрокристаллов и наличия металлического покрытия на торце микрокристалла. К существенному уменьшению пороговой мощности возникновения лазерной генерации может привести использование различных форм активного элемента на основе $\mathrm{ZnO}$, например параллелепипед, цилиндр или шар с размером порядка световой длины волны, помещенный в прозрачную среду с меньшим показателем преломления [22]. Другим возможным способом улучшения пороговых характеристик является легирование металлами микрокристаллов $\mathrm{ZnO}$. Литературных данных о влиянии примеси на пороговые характеристики в $\mathrm{ZnO}$ не обнаружено, однако легирование металлами широко используется с целью увеличения интенсивности люминесценции и возможной настройки длины волны микро- и наноструктур $\mathrm{ZnO}$ в широком диапазоне от УФ до красного [18-20]. Сu имеет электронную структуру, химические и физические свойства, близкие к свойствам Zn [21], поэтому рассматривается как оптимальный допант. Наличие вакансий цинка $V_{\mathrm{Zn}}$ в нанокристаллах оксида цинка ухудшает термическую стабильность люминесцентных характеристик. В [23] показано, что допирование медью, которая заполняет вакансии цинка $\mathrm{Cu}_{\mathrm{Zn}}$, приводит к высокой термической стабильности. В [24] авторы сообщают о синтезе по механизму ПЖК легированных $\mathrm{Cu}$ нанопроволок $\mathrm{ZnO}$ с высоким отношением длины к диаметру и объясняют наблюдаемый пик синего излучения различными валентными состояниями атомов $\mathrm{Cu}$ в $\mathrm{ZnO}$. Нанокристаллы $\mathrm{ZnO}: \mathrm{Cu}$ с различным содержанием $\mathrm{Cu}$ были синтезированы авторами [25], которые сообщают, что 6\% легирование $\mathrm{Cu}$ приводит к образованию фаз $\mathrm{Cu}$ и снижению люминесценции. Легированные медью нанопроволоки $\mathrm{ZnO}$ с низкой концентрацией меди (0.1 at.\%) были получены авторами [21] методом газотранспортного синтеза с медью в качестве катализатора. Авторы наблюдали отчетливый непрерывный спектр фотолюминесценции нанопроволок $\mathrm{ZnO}: \mathrm{Cu}$ в диапазоне от УФ до красного. В [26] авторы синтезировали стержнеобразные нанокри- 
сталлы $\mathrm{ZnO}: \mathrm{Cu}$, которые показали три пика излучения в видимой области при 413, 435 и $531 \mathrm{~nm}$ вместе с пиком ультрафиолетового излучения при $390 \mathrm{~nm}$. Приведенные данные также свидетельствуют о зависимости спектров фотолюминесценции структур оксида цинка от их формы, морфологии массива.

Целью данной работы является проведение исследований зависимости спектрально-генерационных характеристик массива микрокристаллов оксида цинка от их морфологии, степени разупорядочения в массиве, наличия примеси меди.

\section{Материалы и методы}

Выращивание массивов микростержней оксида цинка осуществлялось методом химического осаждения из паровой фазы по механизму ПЖК на лабораторной установке с кварцевым реактором проточного типа диаметром $56 \mathrm{~mm}$ и внешними резистивными нагревателями. Навеску цинка (порошок) в кварцевой лодочке помещали в конец запаянной с одной стороны кварцевой ампулы. С открытой стороны на верхней стенке ампулы имелась широкая щель, напротив которой располагались подложки. В качестве подложек использовали сапфир (0001). Ампулу помещали в горизонтальный кварцевый реактор таким образом, что цинк находился в зоне испарения (температура $T_{2}$ ), а подложки - в зоне роста $\left(T_{1}\right)$. Процесс проводили при пониженном давлении, для чего реактор вакуумировали с помощью форвакуумного насоса до установления стационарного давления ( 10 Pa), затем, не прекращая откачки, пускали аргон (марки ВЧ). Расход аргона составлял 0.41/min. Когда в реакторе устанавливалось стационарное давление, доводили до рабочего значения температуру в зоне роста $T_{1}$. В различных экспериментах $T_{1}$ варьировали от 550 до $630^{\circ} \mathrm{C}$. Далее поднимали температуру в зоне испарения $T_{2}\left(620-650^{\circ} \mathrm{C}\right)$. После выхода на рабочий режим в реактор подавали кислород (ОСЧ). Расход кислорода составлял $10 \%$ от общего расхода газа. В ходе процесса пары цинка поступали из зоны испарения в зону роста, где реагировали с кислородом. Продолжительность синтеза составляла $20 \mathrm{~min}$.

Массивы микрокристаллов оксида цинка были выращены на подложках сапфира (0001), прошедших химикомеханическую полировку; средняя шероховатость поверхности подложек $R_{a} \approx 0.3 \mathrm{~nm}$. Для исследования влияния меди на люминесценцию $\mathrm{ZnO}$ на подложках методом термического испарения в установке ВУП ВН2000 был предварительно сформирован тонкий слой меди толщиной $15 \mathrm{~nm}$, которая определялась с использованием кварцевого датчика толщины КИТП-5 и контролировалась при помощи метода атомно-силовой микроскопии. На поверхность сапфира с металлическим слоем наносилась царапина шириной $\approx 30 \mu \mathrm{m}$. Царапина наносилась стальным скальпелем так, что прорезался только металлический слой. Участок поверхности

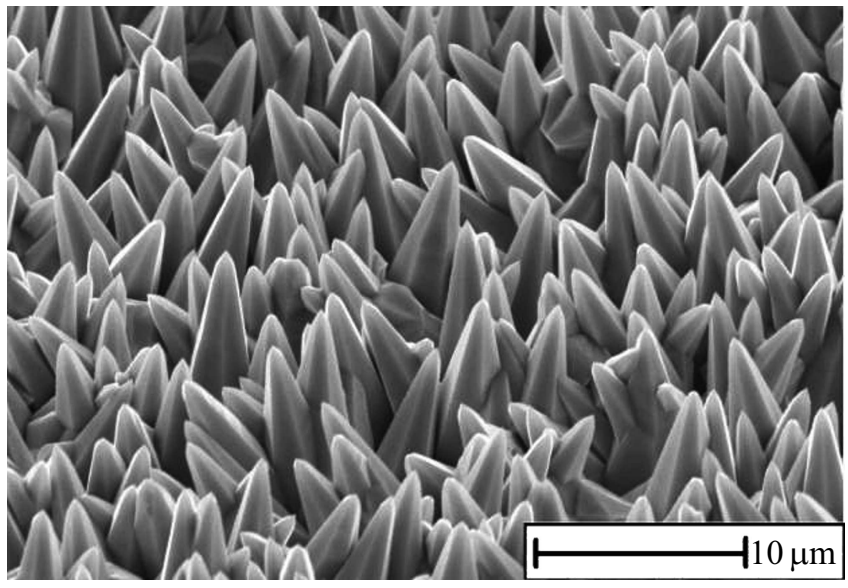

Рис. 1. РЭМ-изображения массивов микрокристаллов оксида цинка, выращенных при $T_{2}=650^{\circ} \mathrm{C}$ на подложках сапфира с нанесенным слоем меди $15 \mathrm{~nm}$. Время синтеза $20 \mathrm{~min}$. Температура подложек во время синтеза $T_{1}=615^{\circ} \mathrm{C}$.

с нанесенной царапиной исследовался методом АCM, толщина нанесенного слоя определялась по профилю, построенному перпендикулярно направлению нанесения царапины.

Электронно-микроскопические исследования и энергодисперсионный микроанализ образцов выполняли с помощью электронного микроскопа Jeol JSM-6000PLUS. Электронная микроскопия использовалась в работе как наиболее информативный метод, позволяющий оценить форму, размеры и взаимную ориентацию элементов выращенных структур.

Спектры излучения в массивах микрокристаллов $\mathrm{ZnO}$ исследовали методом фотолюминесцентной спектроскопии. Для оптического возбуждения излучения в массивах микрокристаллов $\mathrm{ZnO}$ использовалось излучение третьей гармоники лазера $\mathrm{Nd}: \mathrm{YAG}(\lambda=355 \mathrm{~nm}$, диаметр пучка $d \approx 200 \mu \mathrm{m}$, длительность импульса $10 \mathrm{~ns}$, частота повторения $15 \mathrm{~Hz}$ ).

\section{Результаты и обсуждение}

В работе рассматриваются выращенные массивы микрокристаллов $\mathrm{ZnO}$ двух морфологий: призматические (столбчатые, с постоянным сечением) и пирамидальные (заостренные к вершине, игольчатые).

По условиям экспериментов между зоной испарения и зоной роста существует разница температур. Из-за этого попадающие в зону роста пары цинка охлаждаются, что приводит к их частичной конденсации. При поступлении кислорода в зону роста цинк вступает с ним в реакцию. При этом в зависимости от условий проведения процесса могут реализовываться несколько вариантов [26]. В случае избытка кислорода происходит интенсивный рост микрокристаллов $\mathrm{ZnO}$; капли цинка, служащие прекурсорами роста, постепенно уменьшаются вплоть 

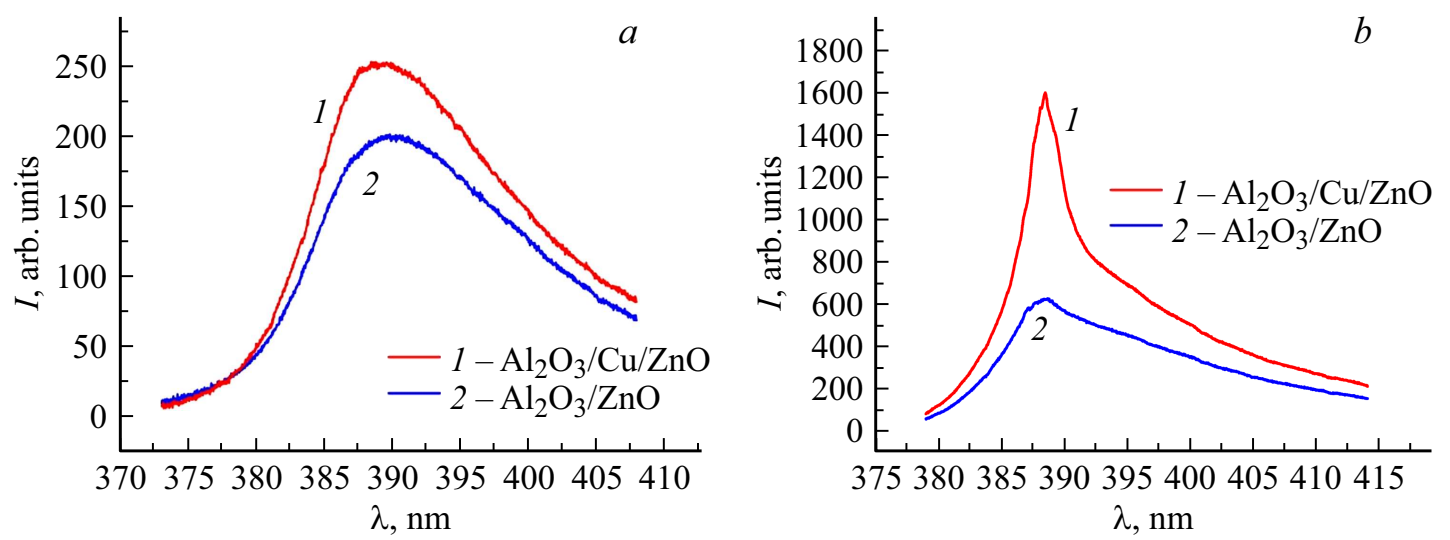

Рис. 2. Спектры излучения массивов микрокристаллов оксида цинка игольчатой формы, выращенных при температуре $T_{1}=615^{\circ} \mathrm{C}$ на подложках сапфира со слоем меди $(15 \mathrm{~nm})$ и без слоя меди. Плотность энергии в импульсе накачки $8.22 \mathrm{~mJ} / \mathrm{cm}^{2}(a)$, $11.07 \mathrm{~mJ} / \mathrm{cm}^{2}(b) . I$ - интенсивность излучения, $\lambda$ - длина волны.
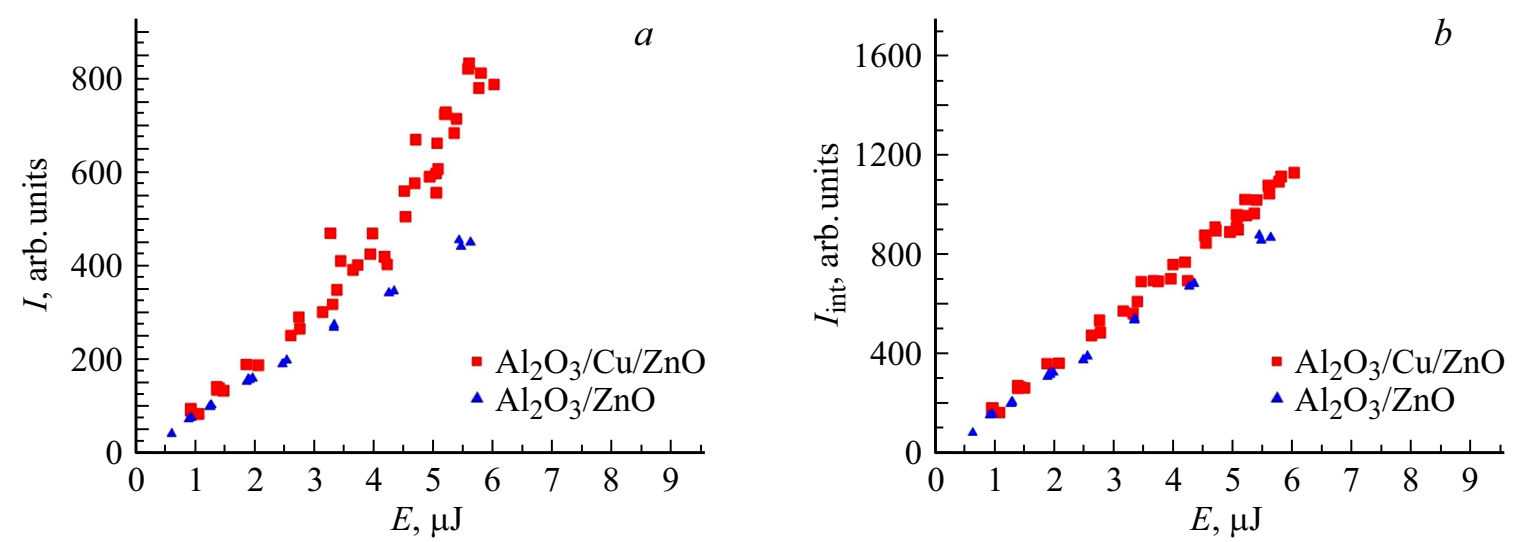

Рис. 3. Зависимость величины максимума интенсивности $(a)$ и интегральной интенсивности $(b)$ излучения микрокристаллов оксида цинка игольчатой формы от величины энергии импульса накачки; со слоем меди $15 \mathrm{~nm}(\boldsymbol{\square})$ и без слоя меди $(\boldsymbol{\Delta})$. $I-$ максимальная интенсивность излучения, $I_{\text {int }}-$ интегральная интенсивность излучения, $E-$ энергия импульса накачки.

до их исчезновения. В таком случае кристаллы $\mathrm{ZnO}$ в процессе роста заостряются, приобретают игольчатую форму. Для получения микрокристаллов призматической формы необходимо добиться стационарных условий, при которых капли цинка в процессе роста будут сохранять свой первоначальный размер.

Микрокристаллы $\mathrm{ZnO}$ игольчатой формы были выращены на подложках сапфира, а также на подложках сапфира с предварительно сформированным слоем меди толщиной $15 \mathrm{~nm}$ при одинаковых условиях синтеза: температура в зоне роста $T_{1}=615^{\circ} \mathrm{C}$, температура в зоне испарения $T_{2}=650^{\circ} \mathrm{C}$, общее давление газовой смеси $\mathrm{Ar}+\mathrm{O}_{2}$ составляло $300 \mathrm{~Pa}$, концентрация кислорода $10 \%$, время синтеза $20 \mathrm{~min}$. РЭМ-изображение микрокристаллов игольчатой формы представлено на рис. 1.

На начальной стадии синтеза после прогрева подложек, но перед подачей в камеру кислорода на подложке со слоем меди жидкий цинк, предположительно, растворяет медь с образованием жидких островков состава $(\mathrm{Zn}+\mathrm{Cu})$. В дальнейшем в процессе роста частицы ме-

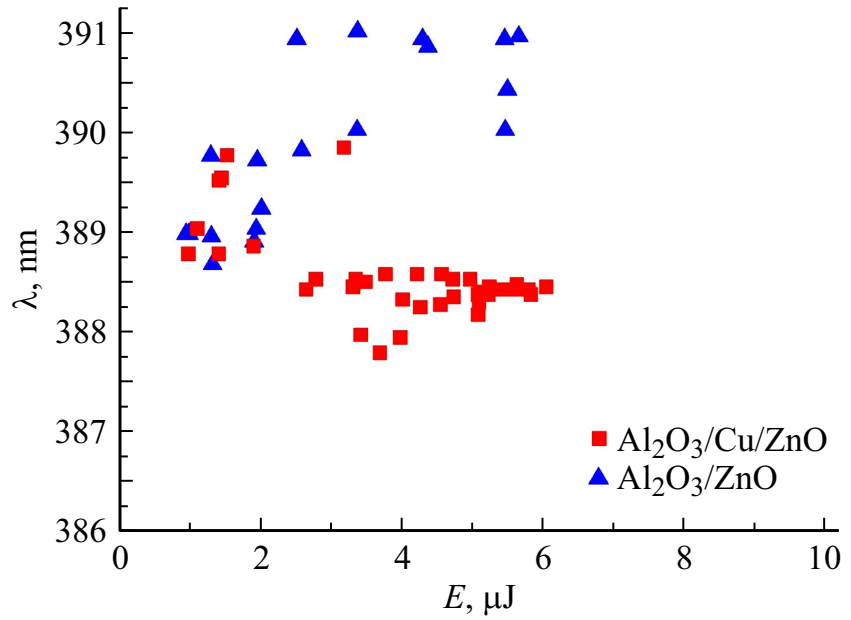

Pис. 4. Длина волны максимума излучения микрокристаллов $\mathrm{ZnO}$ на подложках сапфира со слоем меди $15 \mathrm{~nm}(\boldsymbol{\square})$ и без слоя меди $(\mathbf{\Lambda}) . \lambda-$ длина волны максимума излучения, $E-$ энергия импульса накачки. 

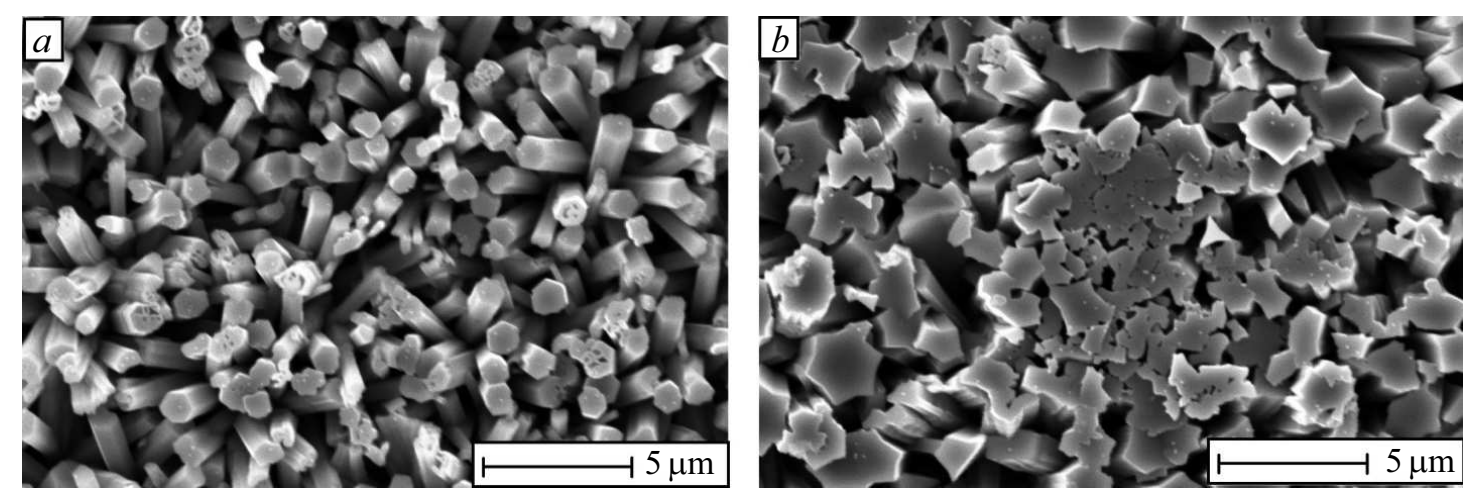

Рис. 5. РЭМ-изображения массивов микрокристаллов оксида цинка, выращенных при $T_{2}=625^{\circ} \mathrm{C}$. Время синтеза 20 min. (a) массив разориентированных микрокристаллов $\mathrm{ZnO}, T_{1}=585^{\circ} \mathrm{C},(b)$ массив микрокристаллов $\mathrm{ZnO}$ с преимущественной ориентацией перпендикулярно поверхности подложки, $T_{1}=560^{\circ} \mathrm{C}$.

ди, входят в состав микрокристаллов $\mathrm{ZnO}$, что подтверждается данными энергодисперсионного микроанализа, который регистрирует концентрацию меди 0.3 at.\%.

На рис. 2 представлены спектры краевого излучения микрокристаллов $\mathrm{ZnO}$ игольчатой формы, выращенных на подложках сапфира с тонким слоем меди и без него. При плотности энергии в импульсе накачки $8.22 \mathrm{~mJ} / \mathrm{cm}^{2}$ (рис. 2,a) спектр излучения состоял из одной полосы, обусловленной спонтанной люминесценцией $\mathrm{ZnO}$. На образцах с медью наблюдалось увеличение интенсивности излучения в сравнении с величиной интенсивности излучения микрокристаллов $\mathrm{ZnO}$, выращенных на подложке без слоя меди.

На рис. 3 представлены зависимости величины максимума интенсивности $(a)$ и величины интегральной интенсивности $(b)$ излучения микрокристаллов $\mathrm{ZnO}$ от энергии накачки. Увеличение интенсивности излучения (обусловленное присутствием меди на подложке) с ростом энергии импульса накачки становится существеннее (рис. 3,a). Следует отметить, наличие меди на подложках сапфира привело к уменьшению порога лазерной генерации $\mathrm{ZnO}$ : на образце с медью лазерная генерация наблюдается при плотности энергии в импульсе $\sim 8.86 \mathrm{~mJ} / \mathrm{cm}^{2}$, в то время как на образце без меди - при плотности энергии в импульсе $\sim 10.76 \mathrm{~mJ} / \mathrm{cm}^{2}$. В [27] авторы сообщают, что медь, встраиваясь в оксид цинка, образует в $\mathrm{ZnO}$ акцепторный уровень, что приводит к появлению зелёной полосы в спектре люминесценции. Нами зелёной полосы в спектрах люминесценции $\mathrm{ZnO}$ обнаружено не было ни на образцах с медью, ни без неё. Стоит также отметить, что наличие меди на подложке привело к смещению максимума излучения микрокристаллов $\mathrm{ZnO}$ в сторону более коротких волн - с 391 до $388.5 \mathrm{~nm}$ (рис. 4).

B [18] авторы описывают незначительное усиление люминесценции наноструктур $\mathrm{ZnO}$, выращенных по механизму ПЖК, однако в их работе сообщается о смещении спектра люминесценции в область более длинных волн на $\sim 7 \mathrm{~nm}$ в образцах наноструктур $\mathrm{ZnO}$, леги- рованных $\mathrm{Cu}$. Авторы связывают это с уменьшением ширины запрещенной зоны $\mathrm{ZnO}$, вызванное легированием $\mathrm{Cu}$, ионы которого заменяют $\mathrm{Zn}$ в узлах кристаллической решетки. На основании вышеизложенного можно предположить, что в нашем случае встраивания меди в структуру микрокристаллов $\mathrm{ZnO}$ не происходит; медь присутствует в микрокристаллах $\mathrm{ZnO}$ или на их поверхности самостоятельно в виде отдельных частиц. Можно предположить, что к росту интенсивности люминесценции приводит переход электронов из $\mathrm{Cu}$ в $\mathrm{ZnO}$. Характер взаимодействия металла и полупроводника в месте их контакта зависит от соотношения их работ выхода $\varphi$. Для $\mathrm{Cu} \varphi=4.53-5.10 \mathrm{eV}$ в зависимости от кристаллического направления [28]. $\varphi \mathrm{ZnO}$ сильно зависит от условий роста: в литературе для образцов $\mathrm{ZnO}$, изготовленных по методу ПЖК, можно встретить значения $\varphi$, лежащие в широком диапазоне от $\sim 4 \mathrm{eV}$ до $5.3 \mathrm{eV}[29-32]$. Это не позволяет точно установить вид контакта $\mathrm{ZnO}$ и $\mathrm{Cu}$ в общем случае и требует дальнейших исследований.

На оптические свойства массивов микрокристаллов $\mathrm{ZnO}$ в значительной степени влияет их морфология [4]. На подложках сапфира с предварительно нанесенным тонким слоем меди при температуре в зоне испарения $T_{2}=625^{\circ} \mathrm{C}$ были выращены два типа массивов микрокристаллов $\mathrm{ZnO}$ призматической формы. На подложках при температуре $585^{\circ} \mathrm{C}$ микрокристаллы представлены изолированными, разориентированными друг относительно друга гексагональными призмами с достаточно четкими гранями (рис. 5,a). По данным РЭМ диаметр стержней $\sim 0.9 \mu \mathrm{m}$, плотность стержней в массиве составляла $\sim 4.7 \cdot 10^{7} \mathrm{~cm}^{-2}$.

В то же время при температуре синтеза $560^{\circ} \mathrm{C}$ наблюдается преимущественная ориентация микрокристаллов $\mathrm{ZnO}$ перпендикулярно поверхности подложки (рис. 5, $b$ ). Микрокристаллы диаметром $\sim 2.2 \mu \mathrm{m}$ формируют закономерные сростки с гранями призмы в качестве плоскостей срастания. Плотность кристаллов $\sim 2.1 \cdot 10^{7} \mathrm{~cm}^{-2}$. 


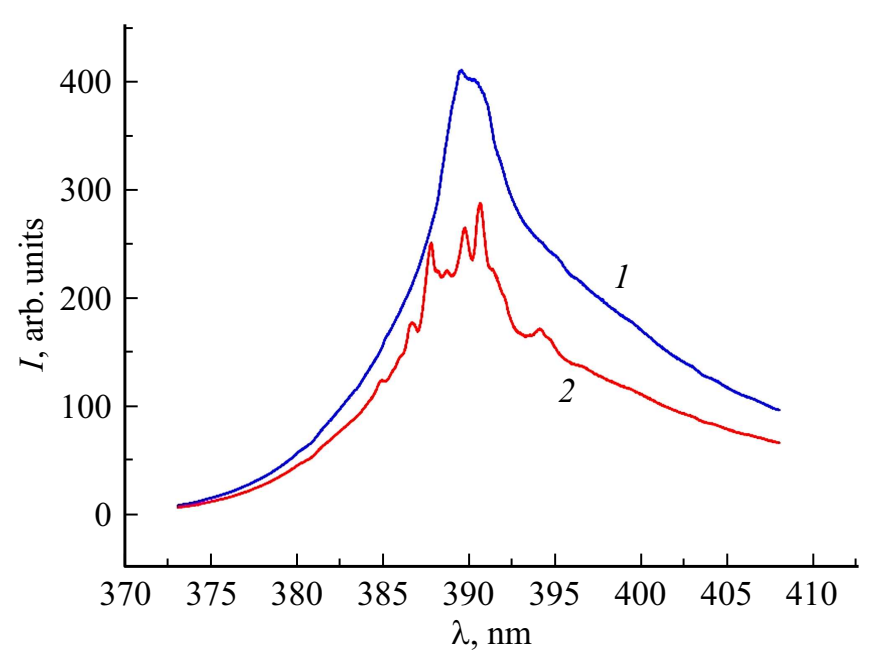

Рис. 6. Спектры излучения массивов микрокристаллов оксида цинка призматической формы, выращенных на подложках с тонким слоем меди; $T_{1}=585^{\circ} \mathrm{C}(1), 560^{\circ} \mathrm{C}$ (2), плотность энергии в импульсе накачки $15.82 \mathrm{~mJ} / \mathrm{cm}^{2} . I$ - интенсивность излучения, $\lambda$ - длина волны.

На рис. 6 приведены спектры излучения массивов стержней $\mathrm{ZnO}$, выращенных при двух температурах синтеза: $1-T_{1}=585^{\circ} \mathrm{C}, 2-T_{1}=560^{\circ} \mathrm{C}$ (плотность энергии в импульсе накачки $15.82 \mathrm{~mJ} / \mathrm{cm}^{2}$ ). Порог лазерной генерации при плотности энергии в импульсе $\sim 2.12 \mathrm{~mJ} / \mathrm{cm}^{2}$ для массива микрокристаллов с преимущественной ориентацией и при плотности энергии в импульсе $\sim 5.69 \mathrm{~mJ} / \mathrm{cm}^{2}$ для массива сильно разориентированных микрокристаллов.

Известно, что в спектрах неупорядоченных массивов микрокристаллов $\mathrm{ZnO}$ наблюдается стохастическая лазерная генерация [15] - лазерный эффект в случайно неоднородной среде [33], в литературе — „random lasing“. При усреднении по множеству импульсов линейчатая структура размывается из-за случайных вариаций спектра от импульса к импульсу накачки, что и наблюдается у нас для разориентированных структур (кривая 1 на рис. 6). В то же время для массивов с преимущественной ориентацией и большим сечением стержней наблюдается генерация, при которой лазерными резонаторами служат сами стержни, лазерные спектры которых не изменяются от импульса к импульсу (кривая 2 на рис. 6).

\section{Заключение}

Исследованы спектры краевого излучения массивов микростержней оксида цинка, выращенных методом химического осаждения из паровой фазы на подложках из сапфира. Структура массивов микрокристаллов $\mathrm{ZnO}$ определялась условиями выращивания. Часть образцов выращивалась на подложках, предварительно покрытых слоями меди нанометровой толщины.
Обнаружено, что при наличии нанометрового слоя меди, предварительно сформированного на подложке сапфира, интенсивность краевого излучения $\mathrm{ZnO}$ несколько увеличивается, порог лазерной генерации понижается, а максимум излучения смещается в область более коротких длин волн. Предположено, что это может быть обусловлено возможным переходом электронов из $\mathrm{Cu}$ в зону проводимости $\mathrm{ZnO}$. В дальнейшем причина эффекта будет детально выясняться.

В массивах микрокристаллов $\mathrm{ZnO}$, выращенных на подложках с предварительно сформированным нанометровым слоем меди и состоящих из случайно ориентированных тонких стержней, при достаточном уровне накачки возникает стохастическая лазерная генерация. В массивах, состоящих из сросшихся ориентированных стержней, возникает генерация, при которой сами стержни играют роль резонаторов.

Работа выполнена при поддержке Федерального агентства научных организаций (соглашение № 007ГЗ/Ч3363/26) в части ,экспериментов по синтезу ансамблей нано- и микрокристаллов на подложках“ и Российского фонда фундаментальных исследований (грант № 16-29-11763 офи-м) в части „характеризация ансамблей нано- и микрокристаллов“ с использованием оборудования ЦКП ИК РАН „Структурная диагностика материалов“.

\section{Список литературы}

[1] Morkoç H., Özgür Ü. Zinc Oxide: Fundamentals, Materials and Device Technology, Weinheim: Wiley, 2009.

[2] Zeng H., Duan G., Li Y. et al. // Adv. Funct. Mater. 2010. N 20. P. 561.

[3] Alivov Y.I., Kalinina E.V., Cherenkov A.E. et al. // Appl. Phys. Lett. 2003. N 83. P. 4719.

[4] Znaidia L., Soler Illia G.J.A.A., Benyahia S. et al. // Thin Solid Films. 2003. N 428. P. 257.

[5] Shan F.K., Yu Y.S. // J. Eur. Ceram. Soc. 2004. N 24. P. 1869.

[6] Chang P.C., Fan Z., Wang D. et al. // Chem. Mater. 2004. N 16. P. 5133.

[7] Lu C.-H., Chao T.-Y., Chiu Y.-F. et al. // Nanoscale Res Lett. 2014. V. 9. N 1. P. 178.

[8] Baranov A.N., Panin G.N., Kang T.W. et al. // Nanotechnology. 2005. N 16. P. 1918.

[9] Kwok W.M., Djurisic A.B., Leung Y.H. et al. // Chem. Phys. Lett. 2005. V. 412. N 1-3. P. 141.

[10] Res S., Bai Y.F., Chen J. et al. // Mater. Lett. 2007. V. 61. N 3. P. 666.

[11] Szarko J.M., Song J.K., Blackledge C.W. // Chem. Phys. Lett. 2005. N 404. P. 171.

[12] Song J.K., Szarko J.M., Leone S.R. et al. // J. Phys. Chem. B. 2005. N 109. P. 15749.

[13] Leung Y.H., Kwok W.M., Djurišic A.B. et al. // Nanotechnology. 2005. N 16. P. 579.

[14] Bando K., Sawabe T., Asaka K. et al. // J. Luminescence. 2004. N 108. P. 385.

[15] Грузинцев А.Н., Редькин А.Н., Макарова З.И. и др. // ФТП. 2007. T. 41. № 6. C. 730. 
[16] Гиваргизов Е.И. Рост нитевидных и пластинчатых кристаллов из пара, М.: Наука, 1977.

[17] Wagner R.S., Ellis W.C. // Appl. Phys. Lett. 1964. N 4. P. 89.

[18] Zhang Z., Yi J.B., Ding J. et al. // J. Phys. Chem. C. 2008. N 112. P. 9579.

[19] Zhu Q., Xie C., Li H. et al. // J. Mater. Chem C. 2014. N 2. P. 4566.

[20] Rodnyi P.A., Khodyuk I.V. // Spectrosc. 2011. N 111 P. 814.

[21] Xu C.X., Sun X.W., Zhang X.H. et al. // Nanotechnology. 2004. N 15. P. 856.

[22] Sung N.E., Kang S.W., Shin H.J. et al. // Thin Solid Films. 2013. N 547. P. 285.

[23] Zhu H., Iqbal J., Xu H. et al. // J. Chem. Phys. 2008. N 129. P. 124713.

[24] Muthukumaran S., Gopalakrishnan R. // Opt. Mater. 2012. N 34 P. 1946.

[25] Raji R., Gopchandran K.G. // Mater. Res. Express. 2017. N 4. P. 25002.

[26] Редькин А.Н., Рызсова М.В., Якимов Е.Е., Грузинцев А.Н. // ФТП. 2013. Т. 47. № 2. С. 216.

[27] Lyons J.L., Alkauskas A., Janotti A. et al. // Appl. Phys. Lett. 2017. N 111. P. 42101.

[28] Lide D.R. // CRC Handbook of Chemistry and Physic. 2005. CRC Press, Boca Raton, FL.

[29] Bai X., Wang E.G., Gao P. et al. // Nanolett. 2003. V. 3. N 8. P. 1147.

[30] Yang X., Lei W., Zhang X. et al. // Physica E. 2009. N 41. P. 1661.

[31] Hwang J.O., Lee D.H., Kim J.Y. et al. // J. Mat. Chem. 2010. V. 21. N 10. P. 3253.

[32] Chen Y., Song X., Li Z. et al. // 29th Int Vac Nanoel Conf. 2016.

[33] Markushev V.M., Zolin V.F., Briskina Ch.M. // Sov. J. Quantum Electron. 1986. N 16. P. 281. 